\title{
$\mathrm{Na}_{2} \mathrm{Se}_{2}$ 을 이용한 대칭적인 다이아릴 다이셀레늄 화합물의 One-Pot 합성방법
}

\author{
이선희 · 김샛별 · 박명숙* \\ 덕성여자대학교 약학대학
}

(접수 2011. 2. 9; 수정 2011. 3. 4; 게재확정 2011. 3. 17)

\section{One-Pot Synthetic Method of Symmetrical Diaryl Diselenides Using $\mathrm{Na}_{2} \mathrm{Se}_{2}$}

Sun-Hee Lee, Saet-Byeul Kim, and Myung-Sook Park*

College of Pharmacy, Duksung Women's University, Seoul 132-714, Korea

(Received February 9, 2011; Revised March 4, 2011; Accepted March 17, 2011)

주제어: 다이아릴 다이셀레늄 화합물, 이중셀레늄 음이온, 유기셀레늄화합물

Keywords: Diaryl diselenides, Diselenide anion, Organoseleniums

서 론

셀레늄은 동물에게 필수미량원소로 인간에게는 암을 예방하는 효능이 있다. ${ }^{1}$ Selenomethionine, selenocysteine 및 무기셀레늄과 같은 셀레늄 $(\mathrm{Se})$ 의 주된 식이원들은 독 성으로 사용이 제한적이기 때문에 합성유도체들이 개발 되어왔다. ${ }^{2}$ 그동안 유기셀레늄에 대한 관심이 계속 증가했 던 이유는 약리학적 연구에서 합성 유기셀레늄 유도체들 이 항산화제, 효소억제제, 신경보호제, 항암제, 항염제 및 면역조절제 등으로 사용될 수 있는 가능성을 나타냈기 때 문이다. ${ }^{3}$ 여러 가지 유기셀레늄 화합물 중에 diphenylmethyl selenocyanate, 1,4-phenylenebis(methylene)-selenocyanate, selenomethionine 및 ebselene은 항암 효과 및 항돌연변이 효 과를 나타내는 것으로 보고되었다.4-6

Diphenyl diselenide는 간단하고 안정한 유기셀레늄 화 합물이고, 여러 가지 약리작용을 갖는 유기셀레늄 화합물 합성에 사용될 수 있는 친전자성 시약이다. Diphenyl diselenide의 합성 및 생리활성에 대한 연구가 최근 활발 하게 연구되고 있으며, 이들의 항산화작용, 간보호작용, 신경보호작용, 항염작용 및 항돌연변이 작용 등 다양한 활성들도 보고되었다. ${ }^{7-9}$

이에 다양한 생리활성 후보물질인 diphenyl diselenide의 구조를 변형시킨 diaryl diselenide 유도체를 설계하여 여 러 가지 유기셀레늄 유도체를 합성한 후, 그 약리효과를 탐색할 필요성이 있는 것으로 보인다. 따라서 본 연구의 목표는 여러 종류의 방향족 고리가 치환된 diselenide계열 의 새로운 유기셀레늄 화합물을 합성하는 것과 이를 위 한 간편한 합성방법을 개발하는데 있다.

\section{결과 및 고찰}

Diselenide계열의 유기셀레늄 화합물들을 제조하기위 해 Bhasin의 합성법을 이용하였다. ${ }^{10,11}$ 최근, K. K. Bhasin 은 bis(2-pyridyl) diselenide를 합성하여 X-ray 결정구조를 밝혔으며, ${ }^{12}$ 이들의 surfactants로서의 가능성을 보고하였다. ${ }^{13}$ 금속 셀레늄을 유기 화합물에 도입하기 위해서 sodium hydroxide와 셀레늄을 반응시켜 $\mathrm{Na}_{2} \mathrm{Se}_{2}$ 를 생성시키고, 연 이어서 aryl halide을 가해 organo selenium 유도체를 제조 한다. K. K. Bhasin의 연구는 반응온도 $120^{\circ} \mathrm{C}$ 에서 2시간동 안 pyridine bromide 유도체와 반응시켜 dipyridyl diselenide 를 합성하였고, 본 실험에서는 반응조건을 다양하게 변화 시켜 최적의 반응온도 및 반응시간을 찾고자 하였다. 또한 pyridinyl기 뿐아니라 4-chloropyridazinyl, benzyl, benzhydryl, 3-chloro-2-pyridinyl, 4-chloro-2-pyridinyl, 2-amino-5-chloro3-pyridinyl 기의 치환기가 들어있는 새로운 diaryl diselenide 유도체를 합성하였다.

$\mathrm{Na}_{2} \mathrm{Se}_{2}$ 를 제조하기 위해서는 DMF에서 셀레늄과 sodium hydroxide를 가한 용액에 hydrazine hydrate를 천천히 적가 한다. 처음 sodium hydroxide와 셀레늄을 DMF에 가하였 을 때, 반응액은 흑색분말인 셀레늄의 영향을 받아 흑색 을 띠게 된다. $\mathrm{Na}_{2} \mathrm{Se}_{2}$ 가 생성되어 반응이 끝나게 되면, 검 녹색으로 변화되는 것을 관찰할 수 있었다.

Scheme 1에서와 같이 diselenide가 형성되는 반응에서, 셀레늄이 한개 도입된 monoselenide가 생성되는 부반응 (3a-3g)을 관찰할 수 있었다. 일반적으로는 diselenide가 주반응 물질로 생성되지만, 화합물 2d, 2e 및 2f의 합성 시 에는 monoselenide가 생성되었다. Monoselenide의 생성여 


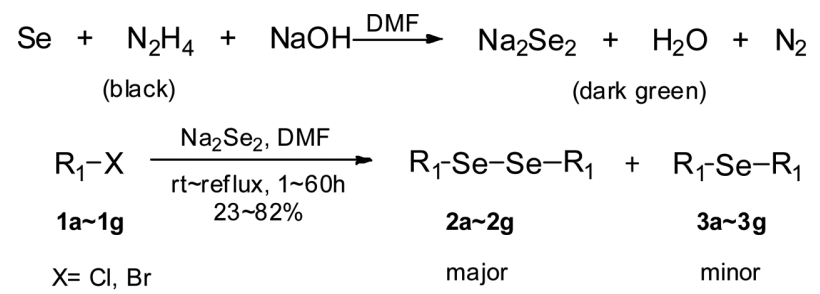

Scheme 1. Formation of diselenides and monodoselenides.

부는 GC-MS로 분석하여 확인하였다. 화합물 $\mathbf{2 a}, \mathbf{2 b}$ 및 $\mathbf{2 c}$ 를 생성하기위한 반응온도와는 다르게 화합물 $\mathbf{2 d}, \mathbf{2 e}$ 및 2f을 제조하기위한 반응온도는 실온이 아닌 환류조건 이었다. 그러나 화합물 $\mathbf{2 g}$ 의 반응은 환류 온도조건이지 만 monoselenide(3g)가 생성되지 않았다. Monoselenide 의 생성이 대부분 고온반응에서 나타난 것으로 보아 반 응의 진행 경로는 온도에 민감한 것으로 생각된다. 실온 반응으로 얻은 화합물 $2 \mathbf{a}, \mathbf{2 b}$ 및 $2 \mathbf{c}$ 에서도 출발물질을 반응액에 빠르게 적가하게 되면, monoselenide가 많이 생성되는 것을 관찰하였다. 이를 보아 적가속도 또한 monoselenide의 생성에 영향을 미치는 것으로 생각된다 (Scheme 1참조). 즉, monoselenide의 생성에는 온도조건 및 적가속도가 영향을 주었다. 따라서 diselenide의 수득 율을 높이기 위해서는 출발물질을 가능한 천천히 적가 시키고, 반응온도를 낮추는 것이 필요하였다. 하지만 반 응물의 구조에 따라 반응온도를 낮추면 반응이 진행되 지 않았다.

일반적으로 $\mathrm{TLC}$ 에서 $R_{f}$ 값은 출발물질이 가장 높았으 며, diselenide, monoselenide 순이었다 $\left(R_{f}\right.$ 값: 출발물질 > diselenide $>$ monoselenide). 녹는점( $(\mathrm{mp})$ 은 diselenide, monoselenide, 출발물질 순으로 높음을 알 수 있었다(mp: diselenide $>$ monoselenide $>$ 출발물질).

본 반응에서 반응 용매로 $\mathrm{DMF}$ 를 사용 한 것은 $\mathrm{Na}_{2} \mathrm{Se}_{2}$ 를 가장 효과적으로 제조할 수 있는 용매이기 때문이다. 그 러나 $\mathrm{DMF}$ 는 끓는점 $\left(153^{\circ} \mathrm{C}\right)$ 이 높아서 반응이 종결된 후 감압농축하여 제거하기가 어렵기 때문에, $\mathrm{DMF}$ 가 유기용 매보다 정제수에 잘 흡착되는 성질을 이용하여 정제수로 세척해 제거하는 방법을 이용하였다. K. K. Bhasin의 합 성 방법에서는 생성물질을 회수하는 유기용매로 diethyl ether를 사용하였으나, 회수율이 낮았고 DMF도 완벽히 제거되지 않았다. 이를 개선하기 위해 여러 유기용매를 사용해본 결과, ethyl acetate가 생성물질 회수와 DMF 제 거에 가장 효과적이었다.

Diselenide의 ${ }^{1} \mathrm{H}$ NMR spectrum을 출발물질 aryl halide 의 ${ }^{1} \mathrm{H}$ NMR spectrum과 비교하였다. 화합물 $\mathbf{2 b}$ 와 $\mathbf{2 c}$ 의 ${ }^{1} \mathrm{H}$ $\mathrm{NMR}$ spectrum에서는 셀레늄이 바로 옆에 치환된 $\mathrm{Se}-\mathrm{CH}_{2}$, $\mathrm{Se}-\mathrm{CH}$ 의 ppm 값이 출발물질의 $\mathrm{Br}-\mathrm{CH}_{2}, \mathrm{Br}-\mathrm{CH}$ 의 ppm 값
과 다른 것을 확인하였다. 그러나 화합물 $2 \mathrm{a}, 2 \mathrm{~d}, 2 \mathrm{e}, \mathbf{2 f}$ 및 $2 \mathbf{g}$ 는 셀레늄이 헤테로고리에 바로 붙어 있어 이와 같은 현상이 나타나지 않았기 때문에, GC-MS와 FT-IR로 diselenide 생성을 확인하였다.

${ }^{1} \mathrm{H}$ NMR에서 monoselenide와 diselenide의 chemical shift 를 나타내는 $\mathrm{ppm}$ 값도 다르게 나타나는 것을 확인하였다. 즉, 화합물 $\mathbf{2 b}$ 와 $\mathbf{2 c}$ 에서 생성된 monoselenide의 $\mathrm{CH}_{2}-\mathrm{Se}-$ $\mathrm{CH}_{2}, \mathrm{CH}-\mathrm{Se}-\mathrm{CH}$ 의 ppm 값과, diselenide의 $\mathrm{CH}_{2}-\mathrm{Se}-\mathrm{Se}-\mathrm{CH}_{2}$, $\mathrm{CH}-\mathrm{Se}-\mathrm{Se}-\mathrm{CH}$ 의 ppm 값은 monoselenide보다 $2 \mathrm{ppm}$ 더 왼 쪽으로 화학적 이동하였음을 확인하였다. FT-IR spectrum 에서는 $760 \mathrm{~cm}^{-1}$ 부근에 $\mathrm{Se}-\mathrm{Se}$ 의 흡수 band가 나타남을 확 인하였다.

본 연구의 합성방법은 one-pot 반응으로 sodium selenide anion을 용시조제하여 곧바로 aryl halide 및 arylalkyl halide 와 반응시켰다. 본 연구의 최종 목적물인 diselenide의 수 득율은 $23 \sim 82 \%$ 로 각 반응별로 편차를 보였다. 고리에 alkyl기가 있는 화합물 $\mathbf{2 b}$ 와 $\mathbf{2 c}$ 의 수득율은 각각 $72 \%$ 와 $83 \%$ 로 비교적 높게 나타났다. 이는 selenide anion의 arylalkyl halide 공격 시 alkyl기의 전자 공여효과로 인한 bromide anion의 이탈이 더 쉽게 일어나기 때문으로 생각된다.

결론적으로 본 연구에서는 다양한 diaryl diselenide를 합성하였고, 이를 위해 $\mathrm{Na}_{2} \mathrm{Se}_{2}$ 를 제조하여 이용하였으며, 생성된 $\mathrm{Na}_{2} \mathrm{Se}_{2}$ 를 분리하지 않고 one-pot으로 aryl halide와 반응을 진행시켰다. 본 연구의 합성방법은 diselenide를 제조하는데 유용할 것으로 생각된다. 또한, 신규 합성된 diselenide 유도체들은 다른 organoselenium 유도체 합성의 중간체로 사용가능하며, 향후 이들의 생리활성을 연구할 예정이다.

\section{실 험}

\section{시약 및 분석기기}

Dichloropyridazine 등 대부분의 시약은 Aldrich사와 Merck 사에서 구입했고, NMR spectrum은 Bruker사의 $300 \mathrm{MHz}$ NMR spectrometer를 사용하여 proton과 carbon nuclear resonance를 측정하였다. 이때 모든 화학적 이동들은 $\mathrm{TMS}$ 를 reference로 하였으며 $\mathrm{ppm}$ 단위로 기록하였다. IR spectrum은 Perkin-Elmer FT-IR Spectrometer Spectrum GX을 사용하여 $\mathrm{NaCl}$ cell로서 thin-film으로 측정하였다. 질량분 석을 위해서는 Agilent $6890 \mathrm{GC}$ 및 $5973 \mathrm{MS}$ 의 GC-MS를 사용하였다. 반응의 진행은 Silica gel $60 \mathrm{~F} 254$ 로 피막된 TLC plate를 이용하여 hexane : ethyl acetate 혹은 methylene chloride : methyl alcohol 등으로 전개시켰으며, spot은 UV light로 확인하였다. 


\section{Di(4-chloropyridazinyl) diselenide 의 합성 (2a)}

Sodium hydroxide $1.50 \mathrm{~g}$ (38.0 mmol)과 selenium 분말 $2.00 \mathrm{~g}$ (25.0 mmol)을 DMF ( $N, N$-dimethylformamide) $30 \mathrm{~mL}$ 에 가하였다. 이 용액에 hydrazine hydrate $0.80 \mathrm{~mL}$ (25.0 mmol) 을 천천히 가한 후, 상온에서 2시간 동안 교반시켜, $\mathrm{Na}_{2} \mathrm{Se}_{2}$ 가 생성되도록 하였다. 이 반응혼합액을 그대로 diselenide 화합물의 합성을 위해 사용하였다. 위에서 제조한 sodium selenide 반응 혼합액에 3,6-dichloropyridazine $3.72 \mathrm{~g} \mathrm{(50.0}$ $\mathrm{mmol})$ 을 천천히 가한 후, 이를 상온에서 60 시간 동안 반 응시켰다. 교반을 멈추고 미반응의 selenium을 가라앉힌 다음에 상등액을 모두 ice water에 가한 후, 그 안에서 결 정화하여 진황색의 결정 $\mathbf{2 a}$ 를 얻었다.

Yield: $43 \%$, mp 180-184 ${ }^{\circ} \mathrm{C} ;{ }^{1} \mathrm{H}$ NMR $\left(\mathrm{CDCl}_{3}\right) \delta 7.98$ (d, $J=9.0 \mathrm{~Hz}, 2 \mathrm{H}), 7.40$ (d, $J=9.0 \mathrm{~Hz}, 2 \mathrm{H}) ;{ }^{13} \mathrm{C} \mathrm{NMR}\left(\mathrm{CDCl}_{3}\right)$ $\delta$ 157.53, 156.21, 130.52, 129.39; FT-IR (NaCl) $\mathrm{cm}^{-1} 3050$ (aromatic), $1583(\mathrm{~N}=\mathrm{N}), 1288(\mathrm{C}-\mathrm{N}), 764(\mathrm{Se}-\mathrm{Se}), 736(\mathrm{C}-\mathrm{Cl})$. GC-MS m/z (\%) $385\left(\mathrm{M}^{+}\right) 272.9$ (42.1), 270.9 (100.0), 268.9 (47.8), 73.1 (33.2).

\section{Dibenzyl diselenide 의 합성 (2b)}

Yield: $72 \%, \mathrm{mp} 82-84{ }^{\circ} \mathrm{C} ;{ }^{1} \mathrm{H}$ NMR $\left(\mathrm{CDCl}_{3}\right) \delta$ 7.32-7.20 (m, 10H, phenyl), 3.79 (d, $\left.J=12.8 \mathrm{~Hz}, 4 \mathrm{H}, \mathrm{CH}_{2}\right) ;{ }^{13} \mathrm{C} \mathrm{NMR}$
$\left(\mathrm{CDCl}_{3}\right) \delta 139.40,129.02,128.44,127.09,32.59\left(\mathrm{CH}_{2}\right)$; FT-IR $(\mathrm{NaCl}) \mathrm{cm}^{-1} 3024$ (aromatic), $1451\left(\mathrm{CH}_{2}\right), 757$ (Se-Se). GCMS $m / z(\%) 342\left(\mathrm{M}^{+}\right) 341.9$ (4.8), 181.1 (8.0), 92 (8.1), 91.1 (100.0), 65.1 (10.7).

\section{Dibenzhydryl diselenide (2c)}

Yield: $82 \%$, mp $118-122{ }^{\circ} \mathrm{C} ;{ }^{1} \mathrm{H}$ NMR $\left(\mathrm{CDCl}_{3}\right) \delta$ 7.32-7.23 (m, 20H), 5.07 (s, 2H, CH); ${ }^{13} \mathrm{C} \mathrm{NMR}\left(\mathrm{CDCl}_{3}\right) \delta 141.43,129.41$, 128.81, 127.67, $27.25(\mathrm{CH})$; FT-IR $(\mathrm{NaCl}) \mathrm{cm}^{-1} 3058$ (aromatic), 3024 (C-H), 744 (Se-Se). GC-MS m/z (\%) $493\left(\mathrm{M}^{+}\right) 168.2$ (15.7), 167.2 (100.0), 166.2 (10.5), 165.2 (27.5), 152.2 (18.4).

\section{Di(2-pyridinyl) diselenide (2d)}

Yield: 61\%, oil; ${ }^{1} \mathrm{H}$ NMR $\left(\mathrm{CDCl}_{3}\right) \delta 8.44(\mathrm{~d}, J=3.0 \mathrm{~Hz}$, 2H), 7.78 (d, $J=7.2 \mathrm{~Hz}, 2 \mathrm{H}), 7.52$ (t, $J=7.9 \mathrm{~Hz}, 2 \mathrm{H}), 7.07$ (q, $J$ $=4.8 \mathrm{~Hz}, 2 \mathrm{H}) ;{ }^{13} \mathrm{C} \mathrm{NMR}\left(\mathrm{CDCl}_{3}\right) \delta 154.81,149.99,137.87$, 123.64, 121.62; FT-IR ( $\mathrm{NaCl}) \mathrm{cm}^{-1} 3041$ (aromatic), 1413 $(\mathrm{C}=\mathrm{N}), 753$ (Se-Se). GC-MS $m / z(\%) 320\left(\mathrm{M}^{+}\right) 236.1$ (45.7), 235.1 (100.0), 233.1 (57.6), 232.1 (25.5), 78.1 (41.6).

\section{Di(3-chloro-2-pyridinyl) diselenide (2e)}

Yield: $62 \%$, mp $39-41{ }^{\circ} \mathrm{C} ;{ }^{1} \mathrm{H}$ NMR $\left(\mathrm{CDCl}_{3}\right) \delta 7.71(\mathrm{~d}, J=$

Table 1. Synthesis of diaryl diselenide compounds using diselenide anion

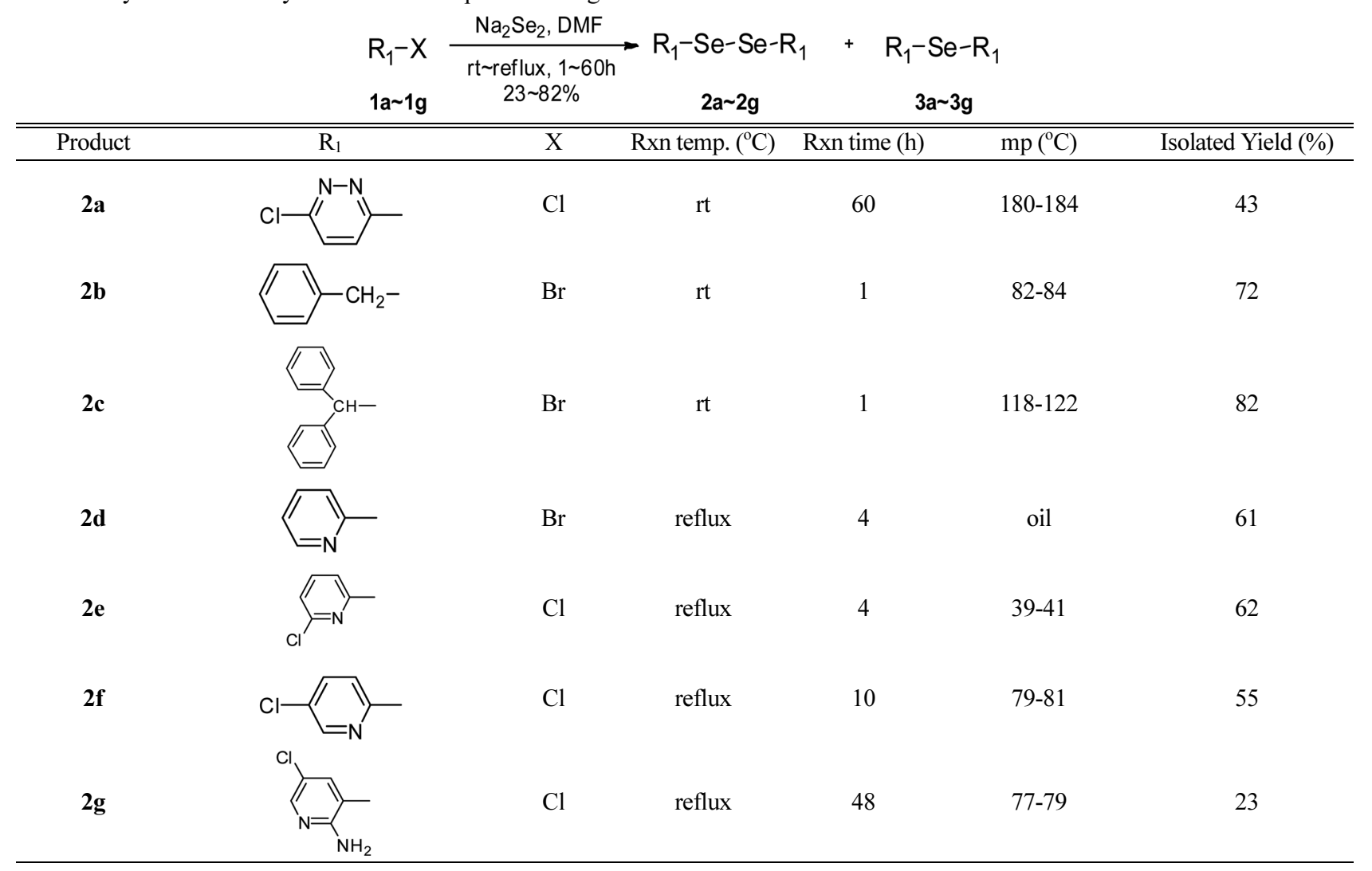


$7.8 \mathrm{~Hz}, 2 \mathrm{H}), 7.50$ (t, $J=7.8 \mathrm{~Hz}, 2 \mathrm{H}), 7.12$ (d, $J=7.8 \mathrm{~Hz}, 2 \mathrm{H})$; ${ }^{13} \mathrm{C}$ NMR $\left(\mathrm{CDCl}_{3}\right) \delta 159.55,149.72,141.14,139.69,123.28 ;$ FT-IR $(\mathrm{NaCl}) \mathrm{cm}^{-1} 2916$ (aromatic), $1401(\mathrm{C}=\mathrm{N}), 763$ (Se-Se), 737 (C-Cl). GC-MS m/z (\%) $384\left(\mathrm{M}^{+}\right) 383.8$ (75.1), 381.9 (59.1), 224.0 (56.2), 189.1 (70.4), 122.1 (100.0).

\section{Di(4-chloro-2-pyridinyl) diselenide (2f)}

Yield: $55 \%, \mathrm{mp} 79-81{ }^{\circ} \mathrm{C} ;{ }^{1} \mathrm{H}$ NMR $\left(\mathrm{CDCl}_{3}\right) \delta 8.41(\mathrm{~s}$, $2 \mathrm{H}), 7.72(\mathrm{~d}, J=9.0 \mathrm{~Hz}, 2 \mathrm{H}), 7.50(\mathrm{~d}, J=8.7 \mathrm{~Hz}, 2 \mathrm{H}) ;{ }^{13} \mathrm{C}$ $\mathrm{NMR}\left(\mathrm{CDCl}_{3}\right) \delta 151.80,148.27,137.11,130.25,124.66$; FTIR $(\mathrm{NaCl}) \mathrm{cm}^{-1} 3045$ (aromatic), $1448(\mathrm{C}=\mathrm{N}), 834(\mathrm{Se}-\mathrm{Se})$, 762 (C-Cl). GC-MS m/z (\%) $384\left(\mathrm{M}^{+}\right) 383.9$ (93.4), 381.9 (72.1), 224.1 (78.9), 189.1 (91.4), 112.1 (100.0).

\section{Di(2-amino-5-chloro-3-pyridinyl) diselenide (2g)}

Yield: $23 \%$, mp $77-79{ }^{\circ} \mathrm{C} ;{ }^{1} \mathrm{H}$ NMR $\left(\mathrm{CDCl}_{3}\right) \delta 7.95$ (s, 2H), $7.51(\mathrm{~s}, 2 \mathrm{H}), 4.93\left(\mathrm{~s}, 4 \mathrm{H}, \mathrm{NH}_{2}\right) ;{ }^{13} \mathrm{C} \mathrm{NMR}\left(\mathrm{CDCl}_{3}\right) \delta$ 153.30, 144.70, 136.40 120.38, 114.98; FT-IR (NaCl) $\mathrm{cm}^{-1}$ $3470 \& 3293\left(\mathrm{NH}_{2}\right), 3153$ (aromatic), $1477(\mathrm{C}=\mathrm{N}), 888(\mathrm{Se}-\mathrm{Se})$, 742 (C-Cl). GC-MS m/z (\%) $414\left(\mathrm{M}^{+}\right), 164.0$ (64.1), 162.0 (100.0), 137.0 (17.8), 135.0 (27.9), 127.0 (33.7).

\section{감사의 글}

이 논문은 덕성여자대학교 2010년도 교내연구비에 의 하여 연구되었습니다. 이에 덕성여자대학교에 감사하는 바입니다.

\section{REFERENCES}

1. (a) Aboul-Fadl, T. Curr. Med. Chem. 2005, 5, 637. (b) Soriano-Garcia, M. Curr. Med. Chem. 2004, 11, 1657. (c)
Brenneisen, P.; Steinbrenner, H.; Sies, H. Mol. Aspects Med. 2005, 26, 256.

2. Tarze, A.; Dauplais, M.; Grigoras I.; Lazard M.; HaDuong N.T.; Barbier F.; Blanquet S.; Plateau, P. J. Biol. Chem. 2007, 282, 875.

3. Nogueira, C. W.; Zeni, G.; Rocha, J. B. Chem. Rev. 2004, 104, 6255.

4. El Bayoumy, K.; Das, A.; Narayanan, B.; Narayanan, N.; Fiala, E. S.; Desai, D.; Rao, C. V.; Amin, S.; Sinha, R. Carcinogenesis 2006, 27, 1369.

5. Huawei, Z.; Gerald, F.; Combs, Jr. J. Nutr. 2008, 19, 1.

6. Karam, E. B.; Raghu, S. Mutation Res. 2004, 551, 181.

7. Rosa, R. M.; Moura, D. J.; Silva, A. C. R.; Saffi, J.; Henriques, J. A. P. Mutation Res. 2007, 631, 44.

8. Freita, A. S.; Funck, V. R.; Rotta, M. S.; Bohrer, D.; Morschbacher, V.; Puntel, R. L.; Nogueira, C. W.; Farina, M.; Aschner, M.; Rocha, J. B. T. Brain Res. Bull. 2009, 79, 77.

9. Stangherlin, E. C.; Favero, A. M.; Weis, S. N.; Zeni, G.; Rocha, J. B. T.; Nogueira, C. W. Food and Chem. Toxicol. 2006, 44, 662.

10. Bhasin, K. K.; Singh, J. J. Organometal. Chem. 2002, $658,71$.

11. Bhasin, K. K.; Singh, N.; Kumar, R.; Deepali, D. G.; Mehta, S. K.; Klapoetke, T. M.; Crawford, M. J. J. Organometal. Chem. 2004, 689, 3327.

12. Bhasin, K. K.; Arora, E.; Kaur, K.; Kang, S. K.; Gobel, M.; Klapoetke, T. M.; Mehta, S. K. Tetrahedron 2009, 65, 247.

13. Mehta, S. K.; Kaur, K.; Arora, E.; Bhasin, K. K. J. Phys. Chem. B 2009, 113, 10686. 